\title{
Reza Hasmath and Jennifer Y.J. Hsu, eds. NGO Governance and Management in China
}

\author{
(London and New York: Routledge, 2016), 202p, \$155 hardcover
}

\author{
Zhenqing Zhang ${ }^{1}$
}

Published online: 18 February 2017

C The Author(s) 2017. This article is published with open access at Springerlink.com

This ten-chapter edited volume is a useful addition to the current scholarship on the relationship between Chinese NGOs and the Chinese state. The volume is divided into three inter-related parts: the general political and economic environment for the emergence of Chinese NGOs, state-NGO engagement in China, and functions of Chinese NGOs. Hsu and Hasmath point out in the introduction chapter that "[as the mediators between Chinese state and society,] there is substantial room for NGOs to navigate, adapt and establish new types of relationships with the state" (p.7). They also argue that "the success in resolving [social problems in China] will also depend on how well central and local authorities respond to the presence and innovation of NGOs" (p.7).

In chapters 2 to 4 , the contributing authors trace the emergence and evolution of NGOs in contemporary China. In chapter 2, instead of seeing NGOs as opponents to the state, Jennifer Hsu advocates an approach that can "theorize the state and NGOs as mutually constitutive within the broader context of state-society relations and state transformation" (p10). She finds that the Chinese state at the local level creates niches and spaces for the NGOs to grow. In chapter 3, Bingzhong Gao and Xunxiang Xia argue that the growth of Chinese social organizations parallel economic growth since the late 1980s. Despite parallel growth, the Chinese social sector advocated modern and universal values, representing a different value system than the ideology of the Chinese Communist Party (CCP). In chapter 4, Shawn Shieh argues that China is moving from a state-led civil society to a state-managed civil society. For Shieh, if Chinese NGOs and policy entrepreneurs are able to build professional capacity, "it is possible that China's civil society will move towards a 'consultative authoritarian' regime in which 'embedded activism' and a 'critical civil society' co-exist alongside a one-party state" (p.67).

Zhenqing Zhang

zzhang01@hamline.edu

1 Hamline University, 1536 Hewitt Ave, St Paul, MN 55104, USA 
As with the initial discussion of the emergence of Chinese NGOs, the next three chapters provide a more nuanced picture about how the collaborative governance between Chinese state and NGOs evolves through case studies of state outsourcing to NGOs (Teets and Jagusztyn - chapter 5), how the public (dis)trust in Chinese NGOs takes shape (Heurlin - chapter 6), and the mechanisms that lead to a lack of state-NGO collaboration (Hasmath \& Hsu - chapter 7). The authors all attribute greater state-NGO collaboration to the professionalization of NGOs. However, they also find that aspects of the authoritarian political culture, such as intolerance of freedom of organization and expression, negatively influenced trust in NGOs and thus lead to a lack of meaningful state-NGO collaboration.

The last three chapters contemplate different functions of Chinese NGOs and the possibility for future operations. In chapter 8, Timothy Hildebrandt provides insight into the development of NGOs after they achieve initial aims. Patricia Thornton and Carolyn Hsu, in chapters 9 and 10 respectively, ponder the future activities of Partyorganized NGOs and government-sponsored NGOs. The authors in this section find that it is difficult for social groups to remain as traditional non-profits after they achieve their goals; and that the Chinese government uses staff appointments and funding allocation to exert influence on NGOs.

Overall, this volume provides a compelling and nuanced explanation of the development of NGOs in China. The authors based their analysis on rich empirical findings. Despite the merits, this volume would be strengthened by considering the following issues. First, while the authors usefully discuss Chinese NGOs' success in resolving some social problems, what about the social issues that Chinese NGOs did not handle successfully? What explains the lack of success by Chinese NGOs with these issues versus the more successful issues? If the relationship between Chinese state and NGOs are cooperative under some circumstances and at odds under others, what are the scope conditions for collaboration? For example, does the type of NGO help determine this relationship, with less sensitive groups collaborating with the state and more sensitive ones, like civil rights advocacy groups and human rights law firms, facing more control and less cooperation from the state? These groups are likely to play a significant role in shaping Chinese politics and should not be ignored in this analysis.

Finally, although chapters 8 to 10 study aspects of Chinese NGOs' management, it would be helpful to provide a deeper understanding of the organization and operation of Chinese NGOs themselves. Further knowledge of the inner working of Chinese NGOs will help to explicate mechanisms causing both the success of some NGOs and failure of others. Although the authors briefly alluded to these issues in the volume, a more comprehensive exploration of those questions would help researchers achieve a better understanding of state-society relationships in China, with particular relevance for NGO governance and management.

In sum, this edited volume should be praised for its contribution to the study of Chinese NGOs. It would be most helpful for graduate students and scholars interested in civil society and state-society relationships in China. The study of the aforementioned questions by future scholars will further build the extant scholarship on the relationship between Chinese state authorities and NGOs.

Open Access This article is distributed under the terms of the Creative Commons Attribution 4.0 International License (http://creativecommons.org/licenses/by/4.0/), which permits unrestricted use, distribution, and 
reproduction in any medium, provided you give appropriate credit to the original author(s) and the source, provide a link to the Creative Commons license, and indicate if changes were made.

Zhenqing Zhang is an Assistant Professor of Political Science at Hamline University, United States. His research interests include Chinese political economy and civil-military relationship in China. 